\title{
The US7 score is an effective tool of monitoring in patients with rheumatoid arthritis over 6 months of Tocilizumab
}

\author{
Mariam Erraoui $^{1 *}$, Hanan Rkain ${ }^{1,2}$, Ilham Bouaddi ${ }^{1}$, Souad Aktaou ${ }^{1}$, Karima Benbouazza ${ }^{1}$, Samira Rostom ${ }^{1}$, Bouchra Amine ${ }^{1}$, Rachid Bahiri $^{1}$,

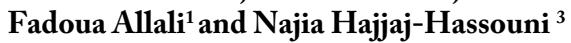 \\ ${ }^{1}$ Rheumatology Department, El Ayachi hospital, Ibn Sina University hospital, Mohammed Vth University Souissi, Morocco \\ ${ }^{2}$ Department of Medicine and Pharmacy, Mohammed Vth University Souissi, Morocco \\ ${ }^{3}$ Centre d'Innovation pédagogique, Université Mohammed VI des Sciences de la Santé, Morocco
}

\begin{abstract}
Objectives: Musculoskeletal Ultrasonography (US) has increasingly been used as an outcome measure in clinical trials of RA. The German ultrasonography 7 (US7) score is a semiquantitative US scoring system that combined soft tissue changes (synovitis and tenosynovitis) and erosive bone lesions in seven preselected joints. We aimed to evaluate clinical and ultrasonographic evolution and their correlation in patients with rheumatoid arthritis (RA) treated with tocilizumab (TCZ) by using the German US7 score.

Methods: Twenty-two consecutive patients, affected by RA [19 females, median age of 41 years $(35,50)$, median disease duration of 72 months (36,171)] who were none or partial responders to methotrexate were commenced on TCZ. The patients underwent clinical, laboratory, and ultrasonographic assessment at 3 visits (baseline and after 3 and 6 months). The Disease Activity Score in 28 joints (DAS28) was recorded at each visit. The German US7 score was performed to assess synovitis, tenosynovitis, erosions and synovial/tenosynovial vascularity. Clinical remission, defined by a DAS $28<2.6$, was assessed at the 3 visits of follow-up.

Results: At baseline, the median DAS28 score was $5.2(4.4,6.2)$ and the synovitis scores were 9.5 $(6.7,15)$ in GS ultrasound and 2.5 $(0,7.2)$ in PD ultrasound. After 6 months of therapy, the DAS28 significantly decreased to $1.6(0.8,2.4) ; \mathrm{p}<0.001$. GS and PD ultrasound scores significantly decreased respectively to $5(4,6) ; \mathrm{p}=0.001$ and to $0.5(0,1.7) ; \mathrm{p}=0.04$.
\end{abstract}

Conclusion: The German US7 is effective to reflect the therapeutic response of RA patients under TCZ as same as clinical and biological findings.

\section{Introduction}

Musculoskeletal ultrasound (US) is a valuable imaging tool in rheumatic diseases. It has become an imaging method that is routinely used in the daily practice of many rheumatologists for both disease activity assessment and therapy monitoring [1-5]. Moreover, Musculoskeletal US has increasingly been used as outcome measures in clinical trials of RA. The German ultrasonography 7 (US7) score is a semiquantitative US scoring system that combined soft tissue changes (synovitis and tenosynovitis) and erosive bone lesions in seven preselected joints.

Tocilizumab (TCZ) is a humanized anti-interleukin 6 (anti-IL 6) receptor antibody that has been demonstrated in previous clinical trials to improve the signs and symptoms of RA and to prevent radiographic progression [6-8].

The objectives of the present follow-up study of RA patients treated with TCZ were to evaluate clinical and ultrasonographic evolution and to explore the correlation between clinical and functional status parameters changes and ultrasonographic findings variations 6 months after TCZ onset basing on the US7 score.

\section{Material and methods}

\section{Patients}

Twenty-two consecutive patients (19 women and 3 men) who fulfilled the American College of Rheumatology 1987 revised criteria for RA [9] were included. The patients gave written consent according to the Declaration of Helsinki, and the study was approved by the local ethics committee.

The patients have a median age of 41 years $(35,50)$ and a median disease duration of 72 months $(36,171)$. These patients who were non-responders or partial responders to methotrexate or having digestive intolerance to this Disease-Modifying Antirheumatic Drugs (DMARDs) were commenced on TCZ.

Each patient received intravenous injections of monotherapy (8 $\mathrm{mg} / \mathrm{kg}$ intravenously every 4 weeks). The doses of the other drugs that each patient was taking were not changed during the study period. Patients had received stable doses of methotrexate for $\geq 8$ weeks prior to study entry. Oral glucocorticosteroids $(\leq 10 \mathrm{mg} /$ day prednisone equivalent) and nonsteroidal anti-inflammatory drugs (NSAIDs) were permitted.

${ }^{\star}$ Correspondence to: Mariam Erraoui, Rheumatology department, El Ayachi hospital, Ibn Sina Universitary hospital, Mohammed Vth University Souissi, Rabat, Morocco, E-mail: mariama_erraoui@yahoo.fr

Key words: German US7, Rheumatoid arthritis, tocilizumab

Received: May 02, 2019; Accepted: September 20, 2019; Published: September 24,2019 


\section{Clinical and laboratory assessment}

Patients underwent clinical and laboratory assessment at 3 visits (baseline, 3 and 6 months after TCZ onset). Disease activity evaluation was performed by using the visual analog scales with values ranging from 0 to $100 \mathrm{~mm}$ for pain, patient and physician global assessments of disease activity. Functional status was assessed using the validated Moroccan version of the health assessment questionnaire (HAQ) [10]. Clinical assessment was determined by an independent physician experienced in the joint assessment.

Standard laboratory tests included erythrocyte sedimentation rate (ESR) determined by using the Westergren method and C-reactive protein (CRP) levels measured by using nephelometry. The Disease Activity Score in 28 joints (DAS28) was used to assess disease activity at each visit. Clinical remission was defined by a DAS $28<2.6$ [11].

\section{Ultrasonographic examination}

US was performed with Toshiba Xario (SAA-660A) using a highfrequency $14 \mathrm{MHz}$ linear array transducer with power Doppler unit. The US study was performed by two experienced rheumatologist sonographers (S.A and H.R) who were blinded to the clinical and laboratory findings in each patient. In addition, power Doppler (PD) was used with the following settings: PRF $0.7 \mathrm{KHz}$, gain $18-30 \mathrm{~dB}$, low filter. The US was performed at the 3 visits (baseline, after 3 and 6 months).

The German US7 score was used to monitor RA activity. This 7 -joint score by Backhaus et al. was evaluated in a longitudinal multicenter German study and found to reflect disease activity and therapeutic response [12]. The German US7 score is the first score that combines soft tissue changes such as synovitis and tenosynovitis as well as erosive bone lesions in a single US scoring system. This score includes an examination of the wrist, metacarpophalangeal (MCP) 2 and 3, proximal interphalangeal (PIP) 2 and 3, and metatarsophalangeal (MTP) 2 and 5 joints at the clinically dominant side with an assessment of synovitis, Paratenonitis /tenosynovitis and erosions [12].

Synovitis and synovial/tenosynovial vascularity were scored semiquantitatively (grade 0-3: $0=$ absence, $1=$ mild, $2=$ moderate,
$3=$ severe synovitis) by grayscale (GS) and power Doppler (PD) ultrasound. Tenosynovitis and erosions were scored for presence. The scoring range was 0-27 for GS synovitis, 0-39 for PD synovitis, 0-7 for GS tenosynovitis, $0-21$ for PD tenosynovitis, and 0-14 for erosions (Table 1).

\section{Statistics}

Statistical analysis was performed with SPSS statistical software, version 17.0 (SPSS, Chicago, IL). For quantitative parameters, we used the mean SD and range. RA activity, functional status, and US findings were compared between M0, M3 and M6 using ANOVA Variations of disease activity ( $\triangle \mathrm{DAS} 28$ ) and US7 scores ( $\triangle$ GUS7) between M0 and M6 were achieved. The Pearson product-moment correlation was used to calculate the correlation between $\triangle \mathrm{DAS} 28$ and $\triangle$ GUS7. $P$ values less than 0.05 were considered statistically significant. Inter- and an intra-reader agreement was calculated using kappa coefficients between the readers. Responsiveness was visualized by use of simple error bar plots with $95 \%$ confidence interval. A mean kappa value of 0.85 was reached for the qualitative (yes/no) scoring of images by the 2 US readers. A mean kappa value of 0.74 was obtained for semiquantitative intra-reader testing of 5 images with signs of synovitis in GSUS, PDUS, and erosions. In addition, the interreader agreement was good: In the detection of erosions, kappa of 0.79 was achieved.

\section{Results}

Patients received a mean daily dosage prednisone equivalent of $7.5 \mathrm{mg}(5,10)$. They have all received efficient doses of Methotrexate before the study. Clinical, laboratory and US data examined at the 3 visits (baseline and after 3 and 6 months) are shown in Tables 2 and 3. At baseline, the median DAS28 score was $5.2(4.4,6.2)$ and the synovitis scores were $9.5(6.7,15)$ in GS ultrasound and $2.5(0,7.2)$ in PD ultrasound. After 6 months of therapy, the DAS28 significantly decreased to $1.6(0.8,2.4) ; \mathrm{p}<0.001$. Remission prevalence has increased significantly from $4 \%$ at baseline to $70 \%$ at M6 (Figure 1). Furthermore, the GS and PD ultrasound scores significantly decreased respectively to $5(4,6) ; \mathrm{p}=0.001$ and to $0.5(0,1.7) ; \mathrm{p}=0.04$. The mean qualitatively evaluated score erosions remained the same at the 3 visits $(P=0.7)$.

Table 1. Synovitis score assessed at baseline, 3 and 6 months after Tocilizumab therapy by gray scale (GS) and power Doppler (PD) modes, using the German ultrasound score (GUS7) adapted from Backhaus, et al [12]

\begin{tabular}{|c|c|c|c|c|}
\hline JOINT & SITES & $\begin{array}{c}\text { SYNOVITIS SCORE } \\
(0-3)\end{array}$ & $\begin{array}{l}\text { POWER DOPPLER SCORE } \\
(0-3)\end{array}$ & $\begin{array}{c}\text { EROSIONS SCORE } \\
\text { (Yes/ No) }\end{array}$ \\
\hline \multirow{3}{*}{ WRIST } & Dorsal & & & \\
\hline & Palmar & & & \\
\hline & Ulnar & & & \\
\hline \multirow{3}{*}{ MCP 2} & Dorsal & & & \\
\hline & Palmar & & & \\
\hline & Radial & & & \\
\hline \multirow{2}{*}{ МCP 3} & Dorsal & & & \\
\hline & Palmar & & & \\
\hline \multirow{2}{*}{ PIP 2} & Dorsal & & & \\
\hline & Palmar & & & \\
\hline \multirow{2}{*}{ PIP3 } & Dorsal & & & \\
\hline & Palmar & & & \\
\hline \multirow{2}{*}{ MTP 2} & Dorsal & & & \\
\hline & Plantar & & & \\
\hline \multirow{3}{*}{ MTP 5} & Dorsal & & & \\
\hline & Plantar & & & \\
\hline & Lateral & & & \\
\hline \multicolumn{2}{|c|}{ SUM SCORE } & 127 & / 39 & $/ 14$ \\
\hline
\end{tabular}


Table 2. Clinical and laboratory parameters in 22 patients treated with Tocilizumab at M0, M3 and M6

\begin{tabular}{|c|c|c|c|}
\hline US scores/ disease activity & M0 & M3 & M6 \\
\hline ESR, mm/hour & $23.5(14.7,50)$ & $3(2,14.2)$ & $3(2,8)$ \\
\hline CRP level, mg/liter & $10(5.7,21,7)$ & $3(2,3)$ & $3.5(2,5)$ \\
\hline DAS28 & $5.2(4.4,6.2)$ & $1.6(1,3.3)$ & 0.04 \\
\hline HAQ & $1.1(0.5,1.6)$ & $0.5(0.4,1)$ & $1.6(0.8,2.4)$ \\
\hline
\end{tabular}

GSUS and PDUS: gray scale (GS) and power Doppler (PD) modes

*Tested with ANOVA, p significatif if $\leq 0.05$

Table 3. Ultrasonography data of 22 patients treated with Tocilizumab at M0, M3 and M6

\begin{tabular}{|c|c|c|c|}
\hline US scores/disease activity & M0 & M3 & M6 \\
\hline Synovitis score by GSUS (max 27) & $9.5(6.7,15)$ & $8(4,10.7)$ & $5(4,6)$ \\
\hline Synovitis score by PDUS (max 39) & $2.5(0,7.2)$ & $1(0,2)$ & 0.001 \\
\hline Erosion score (max 14) & $6(3,9)$ & $6(3,9)$ & 0.04 \\
\hline Tenosynovitis score $(\max 7)$ & $0(0,0)$ & $0(0,1)$ & $0.7 .7)$ \\
\hline Paratenonitis score $(\max 21)$ & $0(0,0)$ & $0(0,0)$ & $0(0,1)$ \\
\hline Total & $17(11,32)$ & $13.5(11,20)$ & $0(0,0)$ \\
\hline
\end{tabular}

GSUS and PDUS: gray scale (GS) and power Doppler (PD) modes

*Tested with ANOVA, p significatif if $\leq 0.05$

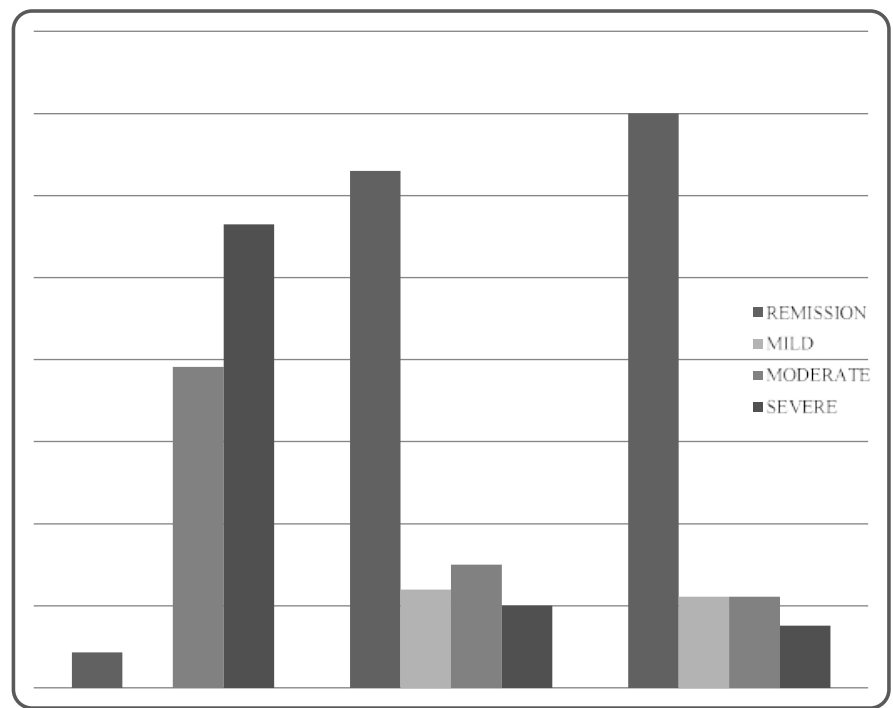

Figure 1. Evolution of RA activity assessed by DAS28 under Tocilizumab at M0, M3 and M6

Tenosynovitis score decreased during the follow-up, but this variation remains statically not significant. Paratenonitis was absent at all visits. (Table 3).

Functional status improved significantly: HAQ changed from 1.1 at M0 to 0.1 at M6 ( $<<0.001)$. Clinical remission was noted in $63 \%$ of patients at M3 and in 70\% of them at M6 (Figure 1). $\triangle \mathrm{DAS} 28$ correlated fairly with $\Delta \mathrm{GUS7}(\mathrm{r}=0.787, \mathrm{p}<0.001)$ (Figures $2-5)$.

\section{Discussion}

The main goals for RA management are to control inflammation and slow or stop the progression of RA $[13,14]$. This study shows that both clinical and ultrasonographic parameters have been significantly improved in patients treated with TCZ. Significant improvement of disease activity was observed after 3 months of treatment by TCZ and was maintained at 6 months of follow-up. Beside disease activity, TCZ gets better functional status: HAQ improved significantly through follow-up. These results are in according to previous data.

Many clinical trials have verified the efficacy of TCZ for patients with RA [6-8, 15-17]. A Cochrane database systematic review concluded that TCZ-treated patients taking concomitant methotrexate were four times more likely to achieve American College of Rheumatology (ACR) 50 improvement and 11 times more likely to achieve DAS remission than patients taking a placebo [6]. Results of recent real-life studies confirm the efficacy of TCZ for the treatment of RA in actual medical practice [17]. With the development of biological modifiers, a growing number of RA patients have been able to achieve remission [13-14]. Nearly two-thirds of our patients achieved remission 3 months after TCZ onset and keep into it.

Nowadays, nobody could contest that the US is a validated and reliable method for assessing joint inflammation [18-20]. Synovitis and effusion are detected by GS (B-mode) and pannus vascularization by use of PD [19]. Earlier data showed US sensitivity to change during treatment with biological medication [1-5].

Many scores are used to evaluate progression in activity and erosions in RA [21]. We have chosen German US7 to be used in US monitoring given that the validity of this score had already been demonstrated [12]. It is also a simple score since it is exploring fewer joints. Hammer and Kvien have already shown that this 7-joint score was as sensitive to change as the 78-joint score (larger and more complete US score) for B-mode and PD assessments [22]. Concerning synovitis and PD. What's extremely important in established rheumatoid arthritis is to monitor its activity in order to adapt adequately to the therapeutic scheme. In our patients treated with TCZ, synovitis and PD scores of the German US7 have improved significantly at M3 with persistent good results at M6.

Our US findings are in according to previously published literature. In preliminary data, Hama and al showed that PD ultrasonography is useful for assessing disease activity and predicting joint destruction in RA patients receiving TCZ [23]. In another study, Kamishima et. al, assessed disease activity in $26 \mathrm{RA}$ patients in the first few months after starting TCZ treatment.

They found that quantitative value for PD signal in the finger joint was responsive and predictive of structural damage progression at 1 year [24].

Our patients suffered from RA with many months of evolution. Therefore, it was not surprising to observe that German US7 erosions score has not varied significantly during the study. Paratenonitis was absent in all US visits. This could be explained by the rarity of this type 
of tendon involvement in RA. Paratenonitis is rather more observed in psoriasis arthritis patients [12].

Presence of positive correlations between clinical disease activity and German US7 score is also relevant for RA monitoring in medical practice.

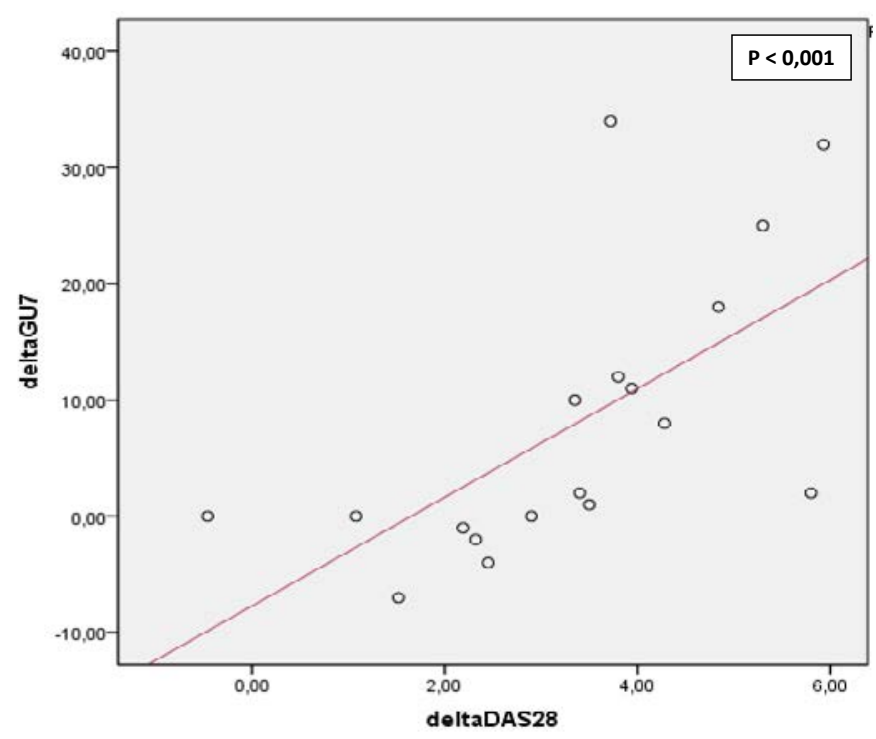

Figure 2. Correlation between $\triangle \mathrm{DAS} 28$ and $\triangle \mathrm{GUS7}$. $\triangle \mathrm{DAS} 28$ : Variations of disease activity between M0 and M6. $\Delta$ GUS7: Variations of GUS7 between M0 and M6

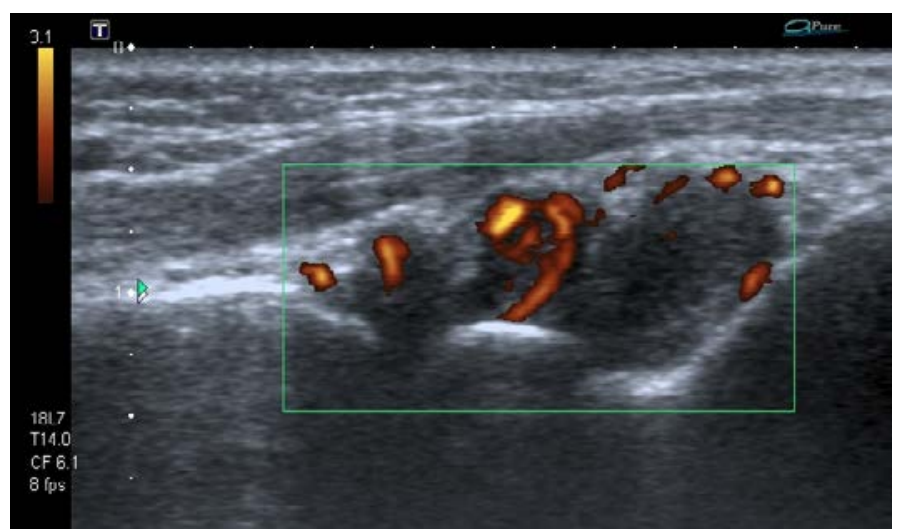

Figure 3. Dorsal sagittal ultrasonography scans of the wrist showing synovial hypertrophy, with hyperemia on Color Doppler

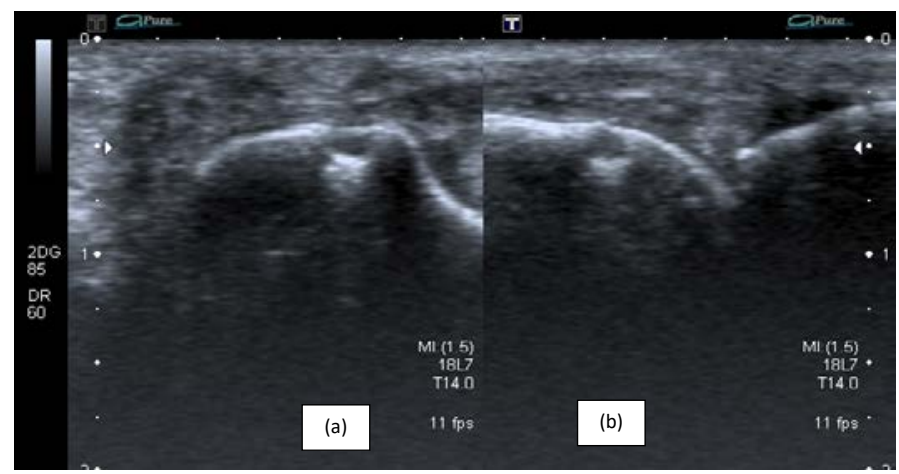

Figure 4. Signs of destruction on ultrasonography in the proximal interphalangeal (PIP) joint: bone erosion is visualized with ultrasonography in the transversal (a) and longitudinal (b) planes

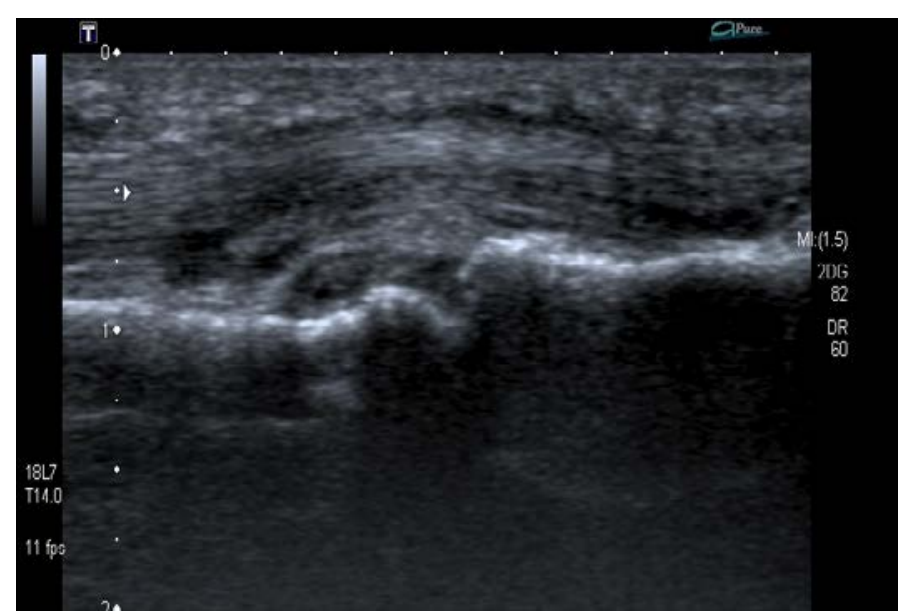

Figure 5. Palmal sagittal ultrasonography scans of the second metacarpophalangeal (MCP) joint showing synovial hypertrophy and tenosynovitis of the flechissor tendon

In summary, our study assessed response to TCZ with a valid US score in a longitudinal design during TCZ treatment and showed both good clinical and US response to TCZ in RA patients.

Some limitations should be pointed out in our study. A limitation of our study is related to the trial being an open-label one, with neither the patients nor the physicians being blinded to the treatment regimen. To minimize this bias, the clinical and US assessments were performed completely independently of each other. Another weakness is the low number of participating patients. However, this number seems to be not negligible in the context of a developing country where access to biotherapy remains limited due to socioeconomic conditions $[25,26]$. However, despite the low number of patients included, the present study was able to detect significant improvements as well in the clinical as in the US scores.

\section{Conclusion}

This study suggests that patients with active RA treated with TCZ showed improvement of their DAS 28, HAQ and ultrasonographic parameters. The German US7 score is a valuable outcome measure of the response of small-joint synovitis and their activity to TCZ. These results should be verified by further studies.

\section{Acknowledgement}

Our work is interesting because it gives information's to both rheumatologists and radiologists about the utility of using ultrasonographic score in monitoring rheumatoid arthritis by using a simple tool which is the US7 score.

\section{References}

1. Ribbens C, Andre B, Marcelis S, Kaye O, Mathy L, et al. (2003) Rheumatoid hand joint synovitis: gray-scale and power Doppler US quantifications following anti-tumor necrosis factor alpha treatment: pilot study. Radiology 229:562-9. [Crossref]

2. Terslev L, Torp-Pedersen S, Qvistgaard E, Kristoffersen H, Røgind H,et al. (2003) Effects of treatment with etanercept (Enbrel, TNRF:Fc) on rheumatoid arthritis evaluated by Doppler ultrasonography. Ann Rheum Dis 62:178-181. [Crossref]

3. Filippucci E, Iagnocco A, Salaffi F, Cerioni A, Valesini G,et al. (2006) Power Doppler sonography monitoring of synovial perfusion at the wrist joints in patients with rheumatoid arthritis treated with adalimumab. Ann Rheum Dis 65:1433-1437. [Crossref]

4. Iagnocco A, Filippucci E, Perella C, Ceccarelli F, Cassarà E, et al. (2008) Clinical and ultrasonographic monitoring of response to adalimumab treatment in rheumatoid arthritis. J Rheumatol 35: 35-40. [Crossref] 
5. Naredo E, Möller I, Cruz A, Carmona L, Garrido J (2008) Power Doppler ultrasonographic monitoring of response to anti-tumor necrosis factor therapy in patients with rheumatoid arthritis. Arthritis Rheum 58: 2248-2256. [Crossref]

6. Singh JA, Beg S, Lopez-Olivo MA (2010) Tocilizumab for rheumatoid arthritis. Cochrane Database of Syst Rev 7: CD008331. [Crossref]

7. Ogata A, Tanaka T (2012) Tocilizumab for the treatment of rheumatoid arthritis and other systemic autoimmune diseases: current perspectives and future directions. Int $J$ Rheumatol 2012: 946048. [Crossref]

8. Ash Z, Emery P (2012) The role of tocilizumab in the management of rheumatoid arthritis. Expert Opin Biol Ther 12: 1277-1289. [Crossref]

9. Arnett FC, Edworthy SM, Bloch DA, McShane DJ, Fries JF, et al. (1988) The American Rheumatism Association 1987 revised criteria for the classification of rheumatoid arthritis. Arthritis Rheum 31:315-324. [Crossref]

10. Abourazzak FE, Benbouazza K, Amine B, Bahiri R, Lazrak N,et al. (2008) Psychometric evaluation of a Moroccan version of health assessment questionnaire for use in Moroccan patients with rheumatoid arthritis. Rheumatol Int 28: 1197-203. [Crossref]

11. Prevoo ML, van't Hof MA, Kuper HH, van Leeuwen MA, van de Putte LB, et al. (1995) Modified disease activity scores that include twenty-eightjoint counts. Development and validation in a prospective longitudinal study of patients with rheumatoid arthritis. Arthritis Rheum 38: 44-48. [Crossref]

12. Backhaus M, Ohrndorf S, Kellner H, Strunk J, Backhaus TM, et al. (2009) Evaluation of a novel 7-joint ultrasound score in daily rheumatologic practice: a pilot project. Arthritis Rheum 61: 1194-201. [Crossref]

13. Combe B, Landewe R, Lukas C, Bolosiu HD, Breedveld F, et al. (2007) EULAR evidence recommendations for the management of early arthritis. Report of a task force of the European Standing Committee for International Clinical Studies Including Therapeutics. Ann Rheum Dis 66: 34-45. [Crossref]

14. Ruderman EM, Nola KM, Ferrell S, Sapir T, Cameron DR (2012) Incorporating the treat-to-target concept in rheumatoid arthritis. J Manag Care Pharm 18: 1-18. [Crossref]

15. Jones G, Sebba A, Gu J, Lowenstein MB, Calvo A, et al. (2010) Comparison of tocilizumab monotherapy versus methotrexate monotherapy in patients with moderate to severe rheumatoid arthritis: the AMBITION study. Ann Rheum Dis 69: 88-96. [Crossref]
16. Burmester GR, Feist E, Kellner H, Braun J, Iking-Konert C, et al. (2011) Effectiveness and safety of the interleukin 6-receptor antagonist tocilizumab after 4 and 24 weeks in patients with active rheumatoid arthritis: the first phase IIIb real-life study (TAMARA). Ann Rheum Dis 70: 755-9. [Crossref]

17. Koike T, Harigai M, Inokuma S, Ishiguro N, Ryu J, et al. (2011) Postmarketing surveillance of tocilizumab for rheumatoid arthritis in Japan: interim analysis of 3881 patients. Ann Rheum Dis 70: 2148-51. [Crossref]

18. Naredo E, Bonilla G, Gamero F, Uson J, Carmona L, et al. (2005) Assessment of inflammatory activity in rheumatoid arthritis: a comparative study of clinical evaluation with grey scale and power Doppler ultrasonography. Ann Rheum Dis 64: 375-381. [Crossref]

19. Wakefield RJ, Balint PV, Szkudlarek M, Filippucci E, Backhaus M, et al. (2005) Musculoskeletal ultrasound including definitions for ultrasonographic pathology. OMERACT 7 Special Interest Group. J Rheumatol 32: 2485-2487. [Crossref]

20. Szkudlarek M, Klarlund M, Narvestad E, Court-Payen M, Strandberg C, et al. (2006) Ultrasonography of the metacarpophalangeal and proximal interphalangeal joints in rheumatoid arthritis: a comparison with magnetic resonance imaging, conventional radiography and clinical examination. Arthritis Res Ther 8: R52. [Crossref]

21. Ohrndorf S, Backhaus M (2013) Advances in sonographic scoring of rheumatoid arthritis. Ann Rheum Dis 72: ii69-ii75. [Crossref]

22. Hammer HB, Kvien TK (2011) Comparisons of 7- to 78-joint ultrasonography scores: all different joint combinations show equal response to adalimumab treatment in patients with rheumatoid arthritis. Arthritis Res Ther 13: R78. [Crossref]

23. Hama M, Uehara T, Takase K, Ihata A, Ueda A, et al. (2012) Power Doppler ultrasonography is useful for assessing disease activity and predicting joint destruction in rheumatoid arthritis patients receiving tocilizumab: preliminary data. Rheumatol Int 32: 1327-33. [Crossref]

24. Kamishima T, Tanimura K, Shimizu M, Matsuhashi M, Fukae J, et al. (2011) Monitoring anti-interleukin 6 receptor antibody treatment for rheumatoid arthritis by quantitative magnetic resonance imaging of the hand and power Doppler ultrasonography of the finger. Skeletal Radiol 40: 745-55. [Crossref]

25. Mody GM, Cardiel MH (2008) Challenges in the management of rheumatoid arthritis in developing countries. Best Pract Res Clin Rheumatol 22: 621-641. [Crossref]

26. Rkain H, Allali F, Jroundi I, Hajjaj-Hassouni N (2006) Socioeconomic impact of rheumatoid arthritis in Morocco. Joint Bone Spine 73: 278-283. [Crossref]

Copyright: $\left({ }_{2} 2019\right.$ Erraoui M. This is an open-access article distributed under the terms of the Creative Commons Attribution License, which permits unrestricted use, distribution, and reproduction in any medium, provided the original author and source are credited. 